\title{
BMJ Open Quality Interprofessional primary care electronic intervention to reduce hypoglycaemic agent use in high-risk veterans with diabetes
}

\author{
Vaibhav Upadhyay, ${ }^{1}$ Evan Walker, ${ }^{1}$ Alayn Govea, ${ }^{1}$ Tessa Rife,${ }^{2}$ Ivette Jimenez, ${ }^{2}$ \\ Maya Dulay, ${ }^{1}$ Jessica Beaman ${ }^{1}$
}

To cite: Upadhyay V, Walker E, Govea A, et al. Interprofessional primary care electronic intervention to reduce hypoglycaemic agent use in high-risk veterans with diabetes. BMJ Open Quality 2018;7:e000221. doi:10.1136/ bmjoq-2017-000221

- Additional material is published online only. To view please visit the journal online (http://dx.doi.org/10.1136/ bmjoq-2017-000221)

Received 27 September 2017 Revised 16 May 2018 Accepted 26 August 2018
Check for updates

(c) Author(s) (or their employer(s)) 2018. Re-use permitted under CC BY-NC. No commercial re-use. See rights and permissions. Published by BMJ.

${ }^{1}$ Department of Internal Medicine, University of California San Francisco, San Francisco, California, USA

${ }^{2}$ San Francisco Veteran's Affairs Medical Center, San Francisco, California, USA

Correspondence to Dr Vaibhav Upadhyay; vaibhav.upadhyay@ucsf.edu and Dr Jessica Beaman; jessica.beaman@ucsf.edu

\section{PROBLEM}

This project aimed to reduce the number of high-risk patients prescribed insulin and/ or sulfonylurea with glycated haemoglobin (HgbAlc) $<7 \%$ in San Francisco Veterans Affairs Health Care System Medical Practice Clinic (SFVAHCS MPC).

\section{BACKGROUND}

Diabetes is a common disease where tight glycaemic control as assessed by HgbA1c must be balanced with the inherent risk of hypoglycaemic events caused by medications like sulfonylureas and insulin. ${ }^{1-3}$ In a previous study conducted in US veterans, a lower HbAlc of $6.9 \%$ compared with $8.4 \%$ had minimal impact on improving health, while increasing risk of at least one hypoglycaemic event $(8.5 \%$ vs $3.1 \%) .{ }^{4}$ Elderly patients, especially those with cognitive or renal impairment, are at highest risk of hypoglycaemic events, which often result in decreased quality of life, loss of consciousness, seizures and altered mental status. ${ }^{5}$ Insulin $(13.9 \%)$ and oral hypoglycaemic agents (10.7\%) were among the four most commonly implicated medications requiring hospitalisations for adverse drug reactions. ${ }^{5}$ Recently, the Veterans Affairs (VA) adapted recommendations from the American Diabetes Association and the American Geriatrics Society's Choosing Wisely initiative to avoid using these medications in high-risk patients with HbAlc $<7.0 \% .^{78}$ Unfortunately, healthcare systems lack clear guidelines on how to enact these recommendations.

\section{BASELINE MEASUREMENT}

A total of 62 patients were identified November 2016 using an internal VA clinical performance dashboard. Eligible patients received primary care at SFVAHCS MPC, had diabetes, were prescribed insulin and/or sulfonylurea, had an HgbA1c $<7 \%$ within the past 6 months and had at least one risk factor for hypoglycaemia: age $\geq 75$, cognitive impairment and/or estimated glomerular filtration rate $(\mathrm{eGFR})<30$. A total of 34 patients were excluded due to recent insulin/sulfonylurea medication change $(\mathrm{n}=21)$, updated HgbA1c $>7 \%(\mathrm{n}=8)$, no longer receiving primary care at SFVAHCS MPC $(n=3)$ and death $(n=2)$. A total of 28 patients met inclusion criteria. Patients were on average $76.9 \pm 5.7$ years of age, had an eGFR of $48.2 \pm 23.7 \mathrm{~mL} / \mathrm{min}$ and $17.8 \%$ had documentation of cognitive impairment $(n=5)$.

\section{DESIGN}

This quality improvement programme was implemented November 2016 through July 2017 by a group of interdisciplinary trainees mentored by interdisciplinary leaders at SFVAHCS MPC. Two Plan-DoStudy-Act (PDSA) cycles were undertaken (figure 1A). A provider-centred intervention was designed after soliciting feedback from providers within SFVA MPC on perspectives regarding hypoglycaemia risk and barriers to HgbA1c management. Because providers were targeted, patient autonomy was maintained. We did not formally measure provider or patient feedback. This project was categorised as quality improvement and not subject to oversight from a Human Subjects Institutional Review Board.

\section{STRATEGY}

PDSA cycle 1: this cycle was conducted from December 2016 to March 2017 (figure 1A). PCPs of eligible patients were contacted via an email template $(n=28)$. The email included a 


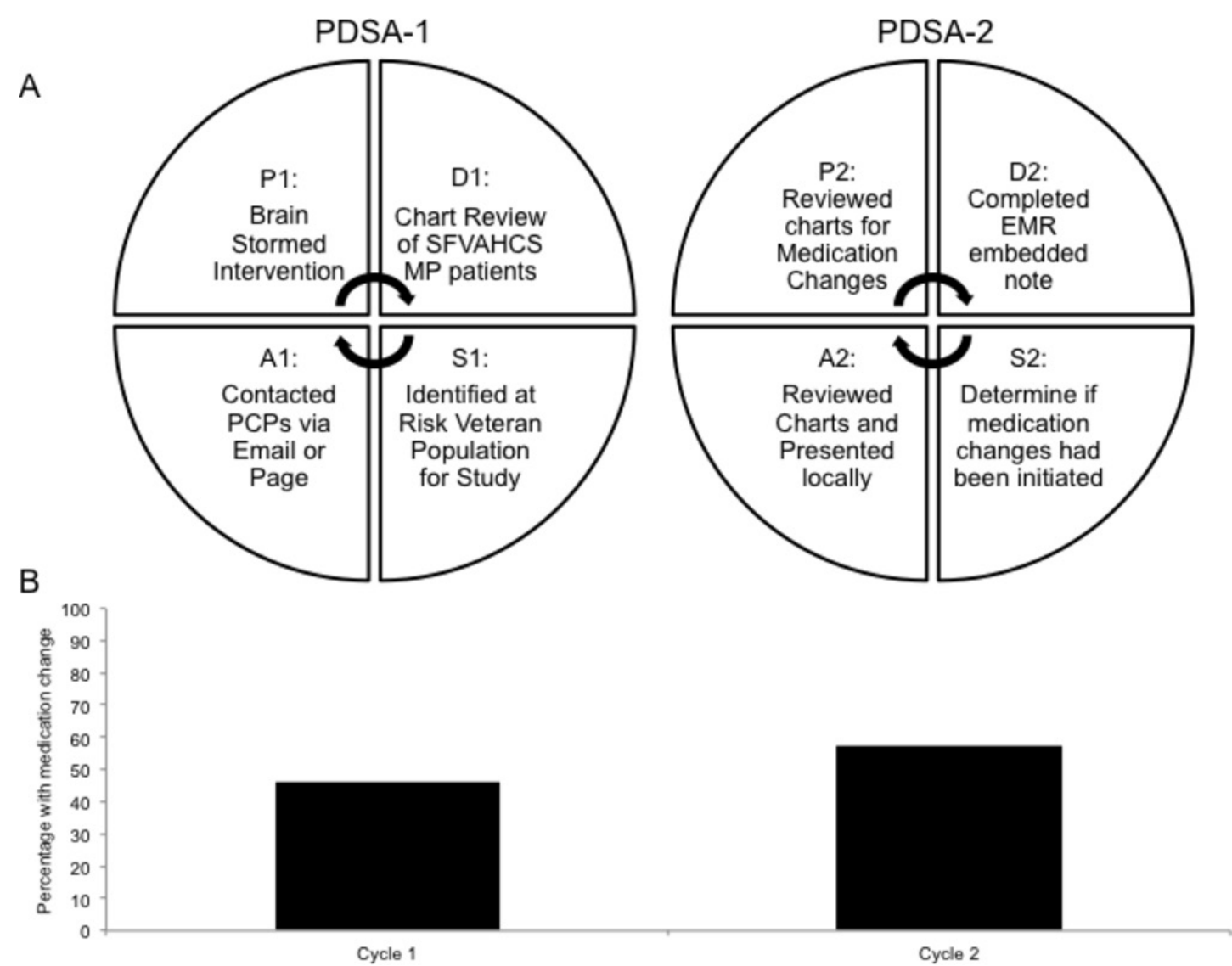

Figure 1 PDSA cycles and cumulative patients with medication changes. (A) PDSA cycles 1 and 2 are plotted (PDSA-1 and PDSA-2. respectively). (B) Cumulative number of patients out of a total of 28 who underwent a medication change plotted by PDSA cycle ( $46 \%$ and $57 \%$ for cycles 1 and 2 , respectively). EMR, electronic medical record; MP, medical practice; PCP, primary care physician; PDSA, Plan-Do-Study-Act; SFVAHCS, San Francisco Veterans Affairs Health Care System.

list of the primary care physician (PCP)'s eligible patients, education on hypoglycaemia risk with insulin and sulfonylureas and recommended three potential strategies to reduce that risk: discontinue sulfonylurea; switch sulfonylurea to saxagliptin, a dipeptidyl peptidase-4 inhibitor with reduced risk for hypoglycaemia; or adjust insulin dosage. We offered electronic pharmacist consultation for individualised recommendations per the PCPs discretion. Ninety-three per cent of providers responded to the initial email. Two providers required additional attempts at contact by page, and one provider did not respond overall. PCPs requested pharmacist electronic consultation for $43 \%$ of patients $(n=12)$, while the remaining $57 \%(\mathrm{n}=16)$ planned to make changes on their own or did not respond. Standardised pharmacist recommendations were individualised to each patient and included: (1) attaining updated HgbAlc, eGFR, and screening for hypoglycaemia if not completed in the past 6 months; (2) relaxing HgbA1c goals $(7 \%-7.5 \%$ in healthy older adults with long life expectancy, $7.5 \%-8 \%$ in those with moderate comorbidity and a life expectancy $<10$ years, or $8 \%-9 \%$ in those with multiple comorbidities and shorter life expectancy); (3) discontinuing or reducing insulin and/or sulfonylurea dosage; (4) switching to saxagliptin; (5) repeating HgbA1c 3-6 months after making a medication change; and (6) offering patient referral to a clinical pharmacist for longitudinal diabetes management. Pharmacists alerted PCPs to their written recommendations in the electronic medical record (EMR).

PDSA cycle 2: this cycle was completed from March 2017 to July 2017 (figure 1A). We reviewed patient charts to determine medication changes and analysed PCP demographics. For patients whose PCPs indicated intent to initiate medication changes without assistance but had not $(n=7)$, a team pharmacist completed electronic consultation using the standardised template and communicated recommendations to the PCP via EMR. Provider demographics reflected a group in varying stages of training: $53 \%$ attending physicians, $31 \%$ medical residents, $9 \%$ geriatrics attending physicians, $5 \%$ nurse practitioner faculty and $2 \%$ nurse practitioner residents.

Study closure: in July 2017, repeat HgbA1c data were available for 26 out of 28 patients. Patients with medication changes are plotted by the PDSA cycle (figure 1B).

\section{POSTMEASUREMENT}

After two PDSA cycles, $57 \%$ patients $(\mathrm{n}=16)$ had deintensification of sulfonylurea or insulin therapy, and this group demonstrated a statistically significant increase in HgbA1c from $6.1 \%$ to $6.9 \%(\mathrm{p}=0.02)$. There was not a meaningful difference between medication changes in 
Table 1 Comparison of patients with and without medication de-escalation

\begin{tabular}{llllll}
\hline $\begin{array}{l}\text { Medication de- } \\
\text { escalation }\end{array}$ & $\begin{array}{l}\text { Mean age } \\
\text { (years) }\end{array}$ & $\begin{array}{l}\text { Mean eGFR (mL/ } \\
\text { min) }\end{array}$ & $\begin{array}{l}\text { Cognitive impairment } \\
\text { diagnosis (n) }\end{array}$ & $\begin{array}{l}\text { Mean prestudy } \\
\text { HgbA1c (\%) }\end{array}$ & $\begin{array}{l}\text { Mean poststudy } \\
\text { HgbA1c (\%) }\end{array}$ \\
\hline No & $76.9 \pm 6.2$ & $50.3 \pm 16.9$ & $1 / 12$ & $6.6 \pm 0.5$ & $7.0 \pm 0.8$ \\
Yes & $76.9 \pm 5.6$ & $46.5 \pm 28.2$ & $4 / 16$ & $6.1 \pm 0.5$ & $6.9 \pm 1.2$ \\
\hline
\end{tabular}

eGFR, estimated glomerular filtration rate; HgbA1c, glycated haemoglobin.

patients whose providers had requested pharmacy input between PDSA cycles 1 and 2 (see the online supplementary figure 1). The group without medication changes only saw a modest increase in HgbAlc from $6.6 \%$ to $7.0 \%$ $(\mathrm{p}=0.08)$. See table 1 for patient details on patients stratified by medication change by enrolment criteria.

\section{SUSTAINABILITY}

Trainee involvement in this quality improvement programme formally ended in July 2017. Prior to study closure, the results of this project were disseminated at an internal conference for quality improvement programmes at SFVAHCS. This information was shared with the VA community and also related quality improvement programmes to ensure sustainability of this intervention over time.

\section{STUDY LIMITATIONS AND UNINTENDED CONSEQUENCES}

This study was conducted at a single primary care clinic within a VA medical centre with colocalisation and frequent in-person interaction between PCPs and pharmacists, which could limit external generalisability. However, most PCPs were part-time in the clinic and most communication was done remotely, which may more accurately portray a larger scale sustainable practice pattern. Another limitation was the reliance on population-level patient health trackers, or a 'patient dashboard', to identify eligible patients. Due to the timing of data collection and study initiation, this method identified patients who at the time of study initiation already had a medication change $(n=21)$. Finally, formal provider and patient feedback was not collected so although provider prescribing patterns towards eligible patients were directly addressed, it remains unknown whether intervention emails led directly to behavioural change or providers were simply waiting for appointments to incorporate changes.

While there are a number of unintended consequences of this study, one worth mentioning is unnecessary QI team and provider interaction. There were a number of providers whose patients were already at goal HgbAlc at study enrolment who were contacted by the QI team. This reflects valuable time and effort lost both on the QI team and provider's behalf.

\section{CONCLUSIONS}

This study demonstrates that a remote intervention targeting PCPs with email and communication via the
EMR can result in substantial change in medication prescribing practice. We had a high PCP response rate to a single email and increased direct involvement of clinical pharmacists. Of 28 participants at risk of a potentially dangerous hypoglycaemic event, 16 (57\%) had a reduction or discontinuation of a high-risk medication during this study and a corresponding increase in A1c. Additionally, this study highlights that societal guidelines can easily be adapted to clinical practice if distilled into a targeted delivery format directly to PCPs using population level health data to demonstrate specifically which patients would benefit from this practice. We demonstrate a scalable approach applicable to chronic disease. Further research is warranted in the general population focused on up scaling to larger medical systems.

Acknowledgements The authors would like to acknowledge the efforts of a large multidisciplinary team collaborating at SFVAHCS who also helped to execute portions of the quality improvement program described here.

Contributors All authors participated in design multiple meetings of the $\mathrm{QI}$ program and helped prepare the manuscript. VU, EW, AG, IJ, TR and other trainees: executed the program and collected results.

Funding The publishing fee for this work was sponsored by the UCSF Open Access Fund.

Competing interests None declared.

Provenance and peer review Not commissioned; externally peer reviewed.

Open access This is an open access article distributed in accordance with the Creative Commons Attribution Non Commercial (CC BY-NC 4.0) license, which permits others to distribute, remix, adapt, build upon this work non-commercially, and license their derivative works on different terms, provided the original work is properly cited, appropriate credit is given, any changes made indicated, and the use is non-commercial. See: http://creativecommons.org/licenses/by-nc/4.0/.

\section{REFERENCES}

1. CDC, 2017. Data \& statistics https://www.cdc.gov/diabetes/data/ index.html (accessed 16 Sep 2017).

2. $\mathrm{NCClH}, 2016$. Symptoms matter-leading causes of disability. https:// nccih.nih.gov/about/strategic-plans/2016/symptoms-matter-leadingcauses-of-disability (accessed 16 Sep 2017).

3. National Center for Health Statistics, 2017. FastStats https://www. cdc.gov/nchs/fastats/leading-causes-of-death.htm (accessed $16 \mathrm{Sep}$ 2017).

4. Duckworth W, Abraira C, Moritz T, et al. Glucose control and vascular complications in veterans with type 2 diabetes. $N$ Engl J Med 2009;360:129-39.

5. Budnitz DS, Lovegrove MC, Shehab N, et al. Emergency hospitalizations for adverse drug events in older Americans. N Engl J Med 2011;365:2002-12.

6. Tseng CL, Soroka O, Maney M, et al. Assessing potential glycemic overtreatment in persons at hypoglycemic risk. JAMA Intern Med 2014;174:259-68.

7. American Geriatrics Society, 2015. Ten things clinicians and patients should question http://www.choosingwisely.org/societies/americangeriatrics-society/ (accessed 16 Sep 2017).

8. American Diabetes Association. 11. Older adults. Diabetes Care 2017;40:S99-S104. 